\title{
artículos
}

\section{La crítica del joven Marx a Hegel. El Manuscrito de Kreuznach}

The young Marx's Critique of Hegel. The Kreuznach Manuscript DANIEL MORENO TONDA Universidad Autónoma de Madrid https://doi.org/10.15366/antitesis2021.1.004 
Recibido: 9/5/2021

Aceptado: 9/6/2021

Resumen. La Crítica a la filosofía del estado de Hegel es un texto de importancia capital para el desarrollo filosófico-político de Marx donde critica a la Filosofía del derecho de Hegel. El articulo abordará tres temas principales: 1) Marx articula su crítica aplicando conceptos e ideas propias de los jóvenes hegelianos, especialmente de Feuerbach con su crítica de la inversión de sujeto y objeto, esto es, la Idea en Hegel es el sujeto y los objetos sus predicados. En la lectura de este borrador inacabado ya se deja entrever los cimientos de la reformulación metodológica entre Hegel y Marx. Sin embargo, esta crítica en muchos casos parte de una visión de Hegel y su teoría ciertamente limitada; 2) Hegel era bien consciente de los nuevos retos que presentaba la incipiente sociedad moderna y orientó su filosofía política a desvelar las contradicciones y ponerles solución bajo el Estado. No obstante, Marx apuntará que Hegel no es capaz de armonizar las particularidades de la sociedad civil y que eventualmente la propiedad privada acaba determinando al Estado; 3) al desterrar de la centralidad la Idea y su encarnación en el Estado hegeliano, Marx, con Feuerbach, propone poner en su lugar al ser humano, de manera que la realización de su esencia política ya no será bajo el Estado monárquico constitucional sino en un Estado democrático y republicano. El articulo pretende dar cuenta de la amplitud de la critica de Marx y, en última instancia, de ponerlo en conexión con las recientes corrientes del «New Hegelian Marxism» destacando la importancia de este manuscrito.

Palabras clave: democracia, propiedad privada, marxismo hegeliano, Estado, sociedad civil

\begin{abstract}
The Critique of Hegel's Philosophy of the State is a text of vital importance for Marx's philosophical-political development where it criticizes Hegel's Philosophy of Right. The article will address three main topics: 1) Marx articulates its critique by using concepts and ideas belonging to the young Hegelians, especially Feuerbach with his critique of the inversion of subject and object, i.e., the Idea in Hegel is the subject and the objects its predicates. In the reading of this unfinished draft, we can already glimpse the foundations of the methodological reformulation between Hegel and Marx. However, this critique suffers in many cases from a vision of Hegel and his theory that is certainly limited; 2) Hegel was very conscious of the new challenges presented by the incipient modern society and oriented his political philosophy to unveil the contradictions and put a solution to them under the State. However, Marx will point out that Hegel is not capable of harmonizing the particularities of civil society and that ultimately private property ends up determining the State; 3) By banishing the centrality of the Idea and its incarnation in the Hegelian State, Marx, with Feuerbach, proposes to locate human beings in its place, so that the realization of their political essence will no longer be under the constitutional monarchical State but in a democratic and republican State. The article aims to give an account of the breadth of Marx's critique and, ultimately, to put it in relation to recent trends of «New Hegelian Marxism» by highlighting the importance of this manuscript.
\end{abstract}

Keywords: democracy, private property, hegelian marxism, State, civil society 


\section{Introducción}

$\mathrm{E}$ 1 Manuscrito de Kreuznach ${ }^{1}$-o Crítica a la filosofía del Estado de Hegel- es un texto de 1843 en el que el joven Marx critica la concepción del Estado de Hegel en su libro Principios de filosofía del derecho. ${ }^{2}$ Comenta casi párrafo por párrafo los pasajes §261-313, es decir, la parte III correspondiente a la Eticidad y más concretamente la tercera sección que versa sobre el Estado. Cabe señalar, sin embargo, que cuando D. Riazanov publica en el Instituto Marx y Engels de la URSS el manuscrito en 1927, las cuatro primeras páginas no estaban, de manera que no tenemos ni el título original que Marx dio al texto ni el comentario a los pasajes $\$ 257-261$. Se da, por tanto, el nombre de $M a$ nuscrito de Kreuznach porque fue redactado en aquella pequeña ciudad alemana cuando Marx, de 25 años, se dirigía al exilio parisino tras ser perseguido por el Estado prusiano. La idea de Marx era realizar un extenso artículo de crítica a Hegel que nunca llegó a ser publicado. ${ }^{3}$ La edición que manejaba Marx era la de Gans de 1833 que ya se difundía por los círculos hegelianos. En ella Gans recogía numerosas adiciones (Zusätze) que son sobre las que, en muchos casos, apunta J. L. Vermal en el prólogo a su edición del libro, trabaja Marx en este texto. Recordemos que el propio Gans dio clases sobre este libro a las que acudió, entre otros, un joven Marx en 1837/38. ${ }^{4}$

Aquí proponemos tres ideas principales que darían cuenta, grosso modo, de la totalidad de la crítica: 1) Marx pretende desvelar las inversiones de sujeto en objeto y viceversa con las que opera Hegel, tomando prestadas las ideas

1 Este texto ha tomado diferentes nombres como Critica a la filosofía del Estado de Hegel o Crítica de la filosofía del derecho público de Hegel o simplemente Manuscrito de Kreuznach; se ha optado por este título ya que apunta más claramente a que el texto que nos ocupa de ninguna manera es una obra acabada, sino un borrador escrito a mano que nunca llegó a la imprenta. Usaremos la siguiente edición: MARX, K., Crítica a la filosofía del Estado de Hegel, Grijalbo, México, 1974.

2 HEGEL, G. W. F., Principios de la filosofía del derecho, Edhasa, Barcelona, 1999.

3 Carta de Marx a Ruge, 5 de marzo de 1842: MARX, K. y ENGELS, F., Collected Works, vol. I, Lawrence \& Wishart, London, 1975, pp. 382-383.

4 DUQUE, F., Historia de la filosofía moderna. La era de la crítica, Akal, Madrid, 1998, p. 810. 
y conceptos principales de la crítica que le realiza Feuerbach, aunque veremos que esta tarea que se impone Marx es algo problemático porque en algunos casos parte de una visión de Hegel que no hace justicia a la verdad; 2) si bien Hegel reconoce que la moderna e incipiente sociedad civil contiene serias amenazas para la vida en comunidad, que son posteriormente armonizadas en un momento superior que sería el Estado, Marx señala que Hegel no consigue contener a la perfección a la sociedad civil y que, de hecho, lo que acaba ocurriendo es que, al revés, es la sociedad civil la que determina al Estado por medio de la propiedad privada; 3) al desterrar de la centralidad la Idea y su encarnación en el Estado hegeliano, Marx, con Feuerbach, propone poner en su lugar al ser humano, de manera que la realización de su esencia política ya no será bajo el Estado monárquico constitucional sino en un estado democrático y republicano.

Al final del epilogo a la segunda edición de El capital escrito en 1873, Marx ajusta cuentas con Hegel, de quien se reivindica discípulo y señala que pretende devolver el ímpetu a su filosofía, la cual había sido tratada, dice, de «perro muerto» por los intérpretes de la época. Ya desde los inicios de su coqueteo con Hegel dedicó sus esfuerzos a criticar el aspecto mistificador de su dialéctica, a ponerla del revés. Una crítica que comenzaba «hace casi treinta años», esto es, en 1843, fecha de nuestro manuscrito. ${ }^{5}$ Aunque en lo que a trasfondo y profundidad filosófica se refiere quizás haya que mantenerse escépticos y recordar que esta caracterización de su dialéctica la ha hecho en un prólogo -y los prólogos son, especialmente para el hegelianismo y el marxismo, las páginas donde sus intérpretes frecuentemente han tomado la parte por el todo dando lugar a numerosas confusiones y malinterpretaciones. Entremos de lleno en el texto para arrojar luz a la siempre interesante y controvertida dupla Hegel-Marx.

\section{Contexto histórico y político de la redacción del manuscrito}

Muchas de las posturas reflejadas en este borrador pueden ser rastreadas en sus artículos periodísticos en la Gaceta Renana (Rheinische Zeitung). Sin embargo, hay que enmarcar este manuscrito en un momento de desintegración del periódico y del proyecto de los jóvenes hegelianos, y de desazón de Marx con la imposibilidad de realizar ningún cambio político sustantivo en Alemania. ${ }^{6}$

5 MARX, K., El capital. Crítica de la economía política, tomo I, vol. I, Siglo XXI, Madrid, 2017, p. 57.

6 Marx en su carta a Ruge desde Kreuznach, septiembre de 1843. MARX, K. y RUGE, A., Los anales franco-alemanes, Martínez Roca, Barcelona, 1970, p. 66: «en Alemania todo lo sofocan a base de violencia, reina una auténtica anarquía espiritual, el régimen de la idiotez misma; y Zúrich obedece las órdenes de Berlín. Consiguientemente, cada vez está más claro que hay que buscar otro centro de reunión para las mentes realmente trabajadoras e independientes. Estoy convencido de que nuestro proyecto se corresponde a una exigencia real, y las 
Marx ha sido ya en el periodo liberal de la Rheinische Zeitung un fuerte crítico de la monarquía prusiana, a la que señala como el principal obstáculo para la equiparación de Alemania con las demás naciones modernas. Ha criticado la estructura eminentemente feudal de las estructuras administrativas y sus leyes que siguen defendiendo intereses privados en base a la organización en estamentos (Stände). En la Introducción de 1844, ${ }^{7}$ apunta que Alemania aún está en su minoría de edad y a lo más que aspira es a una serie de literatos románticos que, desencantados con la Revolución Francesa y su apropiación de Roma, vuelven la cabeza momentáneamente a Grecia, para acabar en la exaltación de la Edad Media como un periodo donde la escisión de los tiempos modernos aún no ha tenido lugar.

Sin embargo, prosigue Marx en la argumentación de la Introducción, ${ }^{8}$ hay un ámbito en el que Alemania puede competir contra las demás potencias europeas: el del pensamiento. ${ }^{9}$ Y más concretamente, es Hegel la punta de lanza de la filosofía alemana. Este fue un filósofo tremendamente revolucionario, piensa Marx. Consiguió crear un sistema filosófico del mundo moderno capaz de desvelar hasta la más escondida de sus contradicciones. Tuvo que bregar con las primeras consecuencias políticas, económicas y sociales del incipiente capitalismo y contribuyó decisivamente a toda la resignificación de los conceptos claves -Koselleck llama a este periodo de 1750-1850: Sattelzeit ${ }^{10}$ para la construcción política e intelectual de la modernidad. Así, no solo Hegel sino todos los pensadores de este momento histórico lidiaron con el nuevo

exigencias reales tienen que satisfacerse en la realidad. Por lo tanto, no dudo de la empresa con tal de que se lleve adelante en serio». La iniciativa de la que hablan es la creación de los Anales Franco-Alemanes (Deutsch-Französische Jahrbücher).

También es ilustrativo de este descontento con la revolución en Alemania una carta previa de Ruge a Marx donde ya le señala la imposibilidad de revolución alguna. En marzo de 1843, desde Berlín: «¿así que vamos a tener una revolución política? ¿Nosotros, los coetáneos de esos alemanes? Amigo mío, usted cree lo que desea. Sí, lo sé, es hermoso confiar, y abandonar las ilusiones es doloroso», ibid., p. 47.

7 MARX, K., Escritos de juventud, Fondo de Cultura Económica, México, 1982.

8 Cabe hacer una advertencia antes de continuar: hay que ser cautelosos con la caracterización del pensamiento de Marx, ya que de un año para otro su pensamiento evoluciona moderadamente; de 1843 a 1844 asistimos a la plasmación concreta de muchas de sus ideas en el plano económico y comienza a hablar ya de proletariado (aún solo como clase política), no hablemos ya de 1844 a 1845/46 cuando se produce la ruptura total con los jóvenes hegelianos. Sin embargo, en cuanto a la caracterización del contexto que hace Marx, este se mantiene prácticamente invariable en sus años de juventud. Por eso es pertinente analizar el contexto de 1843 con la Introducción de 1844 -que, pese a que llevan un nombre parecido, en cuanto a contenido no se parecen tanto.

9 MARX, K., Escritos de juventud, op. cit., p. 495: «somos contemporáneos filosóficos del presente sin ser sus contemporáneos históricos. La filosofía alemana es la prolongación ideal de la historia de Alemania».

10 Véase el estudio introductorio de Antonio Gómez Ramos a: KOSELLECK, R., historia/Historia, Trotta, Madrid, 2010, p. 14 y ss. 
atomismo, la anomia, la individualización, etc., e intentaron superarlo buscando fórmulas para la cohesión social, la falta de guía moral o el problema del Estado y la sociedad civil, recordando los errores del pasado - de la Revolución francesa- que dejaron a los pueblos devastados por el terror y huérfanos de valores comunes. ${ }^{11}$

Sin embargo, Marx considera que el ámbito del pensamiento especulativo no es suficiente para realizar una revolución en Alemania. De la misma manera que Feuerbach había señalado la imperiosa necesidad de negar la conciencia religiosa del mundo moderno para poder desplegar las virtudes del ser humano como ser genérico (Gattungswessen), lo que intenta Marx entonces es rescatar ese potencial revolucionario de Hegel que está mistificado y realizarlo en la praxis política. Esto es, negar a Hegel, ponerlo del revés, invertirlo, desmistificarlo, aunque como ya hemos anticipado, y desarrollaremos más adelante, esta pretensión de Marx parte de una lectura de este muy feuerbachiana y limitada.

El ámbito del pensamiento, la filosofía, la entiende Marx como crítica, como la «crítica despiadada» de todo lo existente. Una crítica no ya abstracta como Hegel y tantos otros jóvenes hegelianos habían propuesto, sino una crítica que consista en negar la teorización indeterminada y tornarse praxis; de la crítica especulativa a la crítica político-práctica. ${ }^{12} \mathrm{Y}$ es que una vez la teoría penetra en las masas es posible negar el aspecto abstracto de la filosofía y realizarla en la praxis, realizar la revolución: «en un pueblo, la teoría sólo se realiza en la medida en que es la realización de sus necesidades». ${ }^{13}$ Serán las masas encarnadas en aquel sujeto llamado proletariado - aún no sociologizado sino que hace referencia a una clase política, aunque ya en la Introducción empieza Marx a hablar del proletariado frente a burguesía- que es el sujeto que nada tiene que perder salvo sus cadenas, es el sujeto de la no-identidad, aquel capaz de negar todo lo existente, aniquilarlo y reconstruirlo. El proletariado, dice aquí ya Marx, puede erigirse como representante de todas las clases - aunque sería más correcto interpretarlo aquí como estamentos- porque no tiene nada en su posesión y, por tanto, no tiene intereses particulares.

\section{Presupuestos teóricos de la crítica}

Es necesario destacar un punto fundamental y es el lugar que ocupa el manuscrito en la obra de Marx. Este hace una férrea oposición, casi sistemática,

11 Véase BEISER, F., The Romantic Imperative, Harvard University Press, Massachusetts/London, 2003, p. 30.

12 Más adelante, en las tesis sobre Feuerbach señalará a la praxis como criterio de la verdad. Tesis II en: MARX, K., La ideología alemana, Akal, Madrid, 2014, p. 500.

13 MARX, K., Escritos de juventud, op. cit., p. 498. 
sin destacar apenas cosas positivas de Hegel -en algunos casos incluso intentando encajar con dificultad su argumentario en un Hegel que explícitamente está ya en contra de lo que Marx le está achacando- porque aún no tiene un sistema filosófico desplegado capaz de integrar a otros. ${ }^{14}$ Aún está sacudiéndose el idealismo hegeliano y sopesando con qué quedarse y con qué no. En este sentido, el texto es relevante porque presenta ciertas rupturas metodológicas que analizaremos más adelante.

Indudablemente Feuerbach es la clave de bóveda de toda la crítica de Marx. Feuerbach argumenta que Hegel quiso derivar la ciencia humana del concepto, de la lógica, y que en su lugar la verdadera ciencia humana ha de ser derivada de la esencia humana: la filosofía de Hegel es la prolongación de la teología; niega al hombre por afirmar a Dios. La conciencia religiosa afirma en Dios lo que niega en el hombre, el hombre no existe por sí mismo, no es el sujeto de su propia existencia. Y como resultado de esto el hombre no puede autodeterminarse, no puede autoconstituirse si ya existe otro sujeto absoluto: Dios. En palabras del propio Feuerbach: «Quien no abandona la filosofia hegeliana, no abandona la teología. La doctrina hegeliana de que la naturaleza, la realidad es puesta por la idea, es únicamente la expresión racional de la doctrina teológica de que la naturaleza es creada por Dios, el ser (Wesen) material por un ser (Wesen) inmaterial, es decir, abstracto». ${ }^{15}$

Sabemos el gran impacto que La esencia del cristianismo y Principios de la filosofía del futuro tuvieron en Marx; él mismo considera estas obras como las más importantes dentro de toda la literatura alemana del momento. ${ }^{16}$ Es a través de Feuerbach que Marx empieza a dar sentido a su materialismo - un materialismo sensualista y antropológico que considera al hombre como sujeto, como ser genérico (Gattungswessen).

Si bien de este materialismo Marx eventualmente acaba escapando y fruto de ello son la Sagrada familia (1844-45), las Tesis sobre Feuerbach (1845) y la Ideología alemana (1845-46), la crítica de Feuerbach a Hegel le acompañará toda la vida. ¿En qué sentido? Feuerbach entendía que Hegel había hecho de la Idea el sujeto de su sistema, de tal manera que habría una sustancia de la que se derivan todos los predicados y la cual supone ya toda la realidad. De esta manera todo está ya predeterminado y presupuesto en la Idea y la Lógica da cuenta solo de cómo se despliega, y de la verdad que genera en este proceso. De suerte que tenemos un sistema donde existe una totalidad que clausura y predispone a su antojo. Y así ha pasado Hegel a la historia de la filosofía como el pensador de lo Absoluto. En el Manuscrito de Kreuznach esta idea está

14 RUIZ SANJUAN, C., Historia y sistema en Marx, Siglo XXI, Madrid, 2019, p. 38.

15 FEUERBACH, L., Principios de la filosofía del futuro, Calden, Buenos Aires, 1969, §52.

16 Carta de Marxa Feuerbach, Paris 11 agosto de 1844; MARX, K., Escritos de juventud, op. cit., pp. 679-682. 
por todas partes, pero también en el Marx de El capital. No hay más que echar un vistazo, de nuevo, al epílogo a la segunda edición de El capital-con la cautela que antes hemos comentado- cuando señala que para Hegel «el proceso del pensar, al que convierte incluso, bajo el nombre de idea, en un sujeto autónomo, es el demiurgo de lo real, lo real no es más que su manifestación externa». ${ }^{17}$ Rompiendo una lanza a favor de Feuerbach diremos que no solo él tuvo esta mala interpretación de un sistema clausurado, sino que desarrollos similares se pueden encontrar en Levinas, Derrida o Karl Popper, entre otros. ${ }^{18}$

Naturalmente, los diferentes seminarios antihegelianos que se produjeron a la muerte de Hegel tuvieron también un gran impacto en toda una generación de jóvenes filósofos. Sin ir más lejos, a los seminarios de Schelling, a quien le habían encargado eliminar «la semilla del dragón panteísta hegeliano» ${ }^{19}$ asistieron, por ejemplo, Ruge, Bakunin o Engels. Es decir, asistió gran parte de los jóvenes hegelianos. Engels no cedió frente a las críticas de Schelling, y así dejó constancia en varios escritos de juventud, como en Schelling sobre Hegel y Schelling y la Revelación, ${ }^{20}$ publicados bajo pseudónimo donde defendía a Hegel -o, mejor dicho, a la escuela de jóvenes hegelianos.

También Feuerbach asistió a las clases de Trendelenburg, el traductor de Aristóteles, con su crítica a la dialéctica hegeliana. No se puede derivar el devenir, decía Trendelenburg, el puro movimiento, de dos polos opuestos y completamente estáticos como el ser y la nada si no está ya presupuesto de antemano el devenir en la relación. Además, por tanto, Hegel no suspende toda presuposición al inicio de la Ciencia de la lógica, sino que intercala elementos empíricos. Los opuestos no pueden ser mediados porque se excluyen absolutamente y solo se podrían mediar, mal que le pese a Hegel, mediante elementos empíricos -y para Marx y Feuerbach esto es lo que termina haciendo este. En efecto, Marx conocía el libro de Trendelenburg de 1840, Investigaciones lógicas, donde expone su crítica a Hegel ${ }^{21}$ y veremos en el artículo partes del manuscrito donde aplica sus ideas.

Finalmente, en cuanto al plano político-jurídico, cabe mencionar la influencia del escrito de 1842 de Arnold Ruge publicado en los Anales alemanes (Deutsch Fahrbücher), La filosofia del derecho de Hegel y la política actual, donde Ruge le critica que hace pasar la historia concreta como un desarrollo lógico de la idea, esto es, el mayorazgo, la monarquía hereditaria y, en definitiva, el Estado prusiano mismo como lo efectivamente real:

17 MARX, K., El capital, op. cit., p. 56.

18 HOULGATE, S., The opening of Hegel's logic, Purdue University Press, Indiana, 2006, pp. 54 y ss.

19 LIEDMAN, S., Karl Marx, Akal, Madrid, 2020, p. 74.

20 ENGELS, F., Escritos de juventud, op. cit., pp. 41-93.

21 ROSSI, M., La scuola hegeliana. Il giovane Marx, Feltrinelli Económica, Milano, 1977, vol. 3 , pp. 55 yss. 
El defecto general de toda la filosofia de Hegel, de ubicarse en un punto de vista teórico, al margen de la historia concreta, es asimismo el de su Filosofía del Derecho. No se puede considerar el Estado en sí y separarlo de la historia, porque toda concepción del Estado y, de una manera más general, toda filosofía, es el producto de la historia. Por esa misma razón, no se puede considerar la Constitución, es decir, una forma determinada del Estado, como una institución eterna y absoluta, porque un Estado determinado sólo constituye un momento de la existencia del Espíritu, que se realiza en él en el plano de la historia. ${ }^{22}$

Este es un punto clave ya que va a situar a Marx en la línea de crítica a Hegel por ser un apologeta del Estado prusiano, quizás el mayor error en este texto. ¿En qué sentido no es exacto considerar a Hegel como un elogiador de lo empírico, esto es, del Estado tal como se presentaba en su momento histórico? De la siguiente manera: a este no le interesa lo existente, lo empírico, la Realität, sino lo actual, la realidad devenida y efectiva, la Wirlichkeit. La famosa sentencia del prefacio a la Filosofia del derecho «lo que es racional es real, y lo que es real es racional» ${ }^{23}$ no es, como ya se ha demostrado en numerosas ocasiones, una oda a la realidad según se presenta y según existe, sino que lo real es autorrealización de la libertad en la práctica. Más claro queda en las Lecciones sobre filosofia de la historia universal cuando dice que «quien mira el mundo racionalmente, ése lo contempla también racionalmente; ambas cosas se determinan mutuamente». ${ }^{24}$ Lo verdadero, lo real, ha de ser desentrañado, exprimido de la Realität, mediante la razón. El Estado, en este sentido, es la realización de la eticidad misma, de la eticidad fáctica. Hegel habla de la idea de Estado, no del Estado del momento; realmente todos los Estados del momento serían Estados fallidos. ${ }^{25}$ La cuestión es que, para Marx, ese devenir en Hegel vendría impulsado por una instancia superior y es en este sentido que señala, con Feuerbach, la vuelta de la religión. Sin embargo, en Hegel no hay tal sustancia o instancia primera supramundana, sino que la razón es radicalmente mundana, inmanente.

De hecho, comenta Marx: «no hay que hacerle un cargo a Hegel porque describe el ser del Estado moderno tal cual es, sino porque da por ser del Estado lo que es. Que lo racional sea real, esto está precisamente en contradicción con la realidad irracional, que en todas partes es lo contrario de lo que expresa y expresa lo contrario de lo que es ella». ${ }^{26}$ Sin embargo, aunque Marx no acepte verlo, está en plena concordancia con Hegel en esto.

22 Citado en: CORNU, A., Carlos Marx y Federico Engels. Tomo I, Los años de infancia y de juventud. La izquierda hegeliana 1818/20-1844, Platina, Buenos Aires, 1965, p. 276.

23 HEGEL, G. W. F., Principios de la filosofía del derecho, op. cit., p. 58.

24 HEGEL, G. W. F., Introducciones a la filosofía de la historia universal, Istmo, Madrid, 2005, pp. 51-53.

25 HEGEL, G. W. F., Principios de la filosofía del derecho, op. cit., \$260.

26 MARX, K., Crítica a la filosofía del Estado de Hegel, op. cit., p. 81. 
Por otro lado, además, tanto Marx como otros jóvenes hegelianos de la época, al centrarse demasiado en desmontar al viejo Hegel como defensor del Estado prusiano, no prestaron tanta atención a ciertos escritos de juventud - como por ejemplo La constitución de Alemania- donde con un rápido vistazo se puede ver que explícitamente Hegel está lejos de apostar por el empírico Estado prusiano. Sobre todo, porque, en caso de que efectivamente lo estuviera glorificando, lo habría hecho con el Estado liberal previo a los decretos de Karlsbad de 1819. Recordemos que la Filosofia del derecho es su filosofía política desplegada en un libro aparte, pero no es el primer lugar donde reflexiona sobre el Estado. Lejos de los escritos de juventud, ya en la Enciclopedia de 1817 en el apartado dedicado a la segunda sección de la filosofía del espíritu objetivo o en los cursos dedicados al Derecho natural y la ciencia del Estado de 1818$1819^{27}$ tampoco se encuentra rastro de glorificación. De hecho, fruto de la censura a las universidades acto seguido en 1820, este profesor de Berlín tuvo que reformular el prólogo, y es en este sentido como habría que entender el cierto aire de conformismo por miedo a represalias políticas con que inicia el libro. En cualquier caso, la cuestión es que a Hegel también le afectó la censura. En otros casos, simplemente, tal como señala Avineri, ${ }^{28}$ Marx no pudo conocer algunas obras de este que fueron publicadas más tarde como System der Sittlichkeit y Realphilosophie por lo que, por ejemplo, se quedó con que la concepción del trabajo en Hegel es estrictamente positiva porque domina la naturaleza, pero en los primeros ensayos políticos también señaló que el trabajo produce alienación. ${ }^{29}$

\section{Sobre la inversión de la Idea en sujeto}

Empecemos por la idea central de la crítica: la inversión del sujeto en objeto, y viceversa, que, si bien es la parte más débil de la crítica, es importante porque pone los cimientos para una futura rearticulación del método marxista - que verá su forma acabada ya en la crítica de la economía política. El Estado, dice Hegel, se escinde en dos esferas finitas, en sus dos nociones, para luego reintegrarlas en el momento del para sí mediante una operación lógica. Familia y sociedad civil es la materia con la que se mediatiza el Estado en

27 HEGEL, G. W. F., Gesammelte Werke, vol. 26/1, Felix Meiner Verlag, Berlin, 2014,

28 AVINERI, S., Hegel's theory of the modern state, Cambridge University Press, New York, 1972, p. 90.

29 De hecho, Hegel atina al señalar a los capitalistas como aquellos «zánganos de la sociedad» que solo consumen y no producen, pero no puede aún desentrañar el porqué de su existencia y lo achaca a «la contingencia, a la impotencia de la naturaleza. En una palabra, dada su ecuación trabajo = valor, ignora por completo la surgencia de la plusvalía y de la tasa decreciente de beneficio». DUQUE, F., Eticidad y estado en el idealismo alemán, Natán, Valencia, 1987, p. 145. 
sus dos esferas ideales. Pero, apunta Marx, es, en última instancia, una mediación consigo mismo, pero en el plano de la especulación; en realidad esto no es más que «el fenómeno de una mediación», ${ }^{30}$ pura apariencia. A juicio de Marx (y Ruge) la idea real opera aquí con un empirismo vulgar que alza el concreto Estado moderno que analiza Hegel como el modelo universal de realización de la Idea. Anulando, paradójicamente, y esto es lo que critica Marx con Ruge, cualquier pretensión de historicismo en la idea del Estado.

Es una mediación consigo mismo porque, dice Marx, siguiendo a Trendelenburg, no puede haber una mediación entre términos que antes se contraponían. Por ejemplo, en el caso del príncipe que mediaría entre el elemento constituyente y el poder gubernativo, como veremos: «¿cómo haría de mediador entre elementos que necesita para su propio termino mediador, para no ser un extremo unilateral? Aquí se presenta toda la absurdidad de esos extremos que desempeñan alternativamente ora el papel de extremo ora el papel de termino mediador». ${ }^{31}$

Respecto de la consideración del Estado como organismo cuyos aspectos diferenciados son asi los diversos poderes con sus tareas y actividades que se relacionan entre sí ${ }^{32}$ dice Marx que, de nuevo, tenemos la inversión lógica ocultada tras la palabra «así». Genera una apariencia fenoménica que hace derivar, de manera lógica, esos poderes del desarrollo y evolución de la idea. Es decir, no dice nada más que volver a señalar su panlogismo. De hecho, cuando Hegel afirma que «el Estado es un organismo, es decir, el desarrollo de la idea en sus diferencias», ${ }^{33}$ no está dando más información sobre la constitución interna del Estado más que ésta deriva de la Idea. No dice nada de su differentia specifica. ${ }^{34}$ El Estado no opera respecto de su naturaleza específica, sino que opera de acuerdo con la naturaleza del concepto. Así, vuela los puentes que podrían hacer pasar «de la idea general del organismo a la idea determinada del organismo del Estado o de la constitución política». ${ }^{35}$

En Hegel es el Estado el que realiza efectivamente esta eticidad, es decir, es el momento donde mejor van a coincidir los intereses individuales con los intereses universales. Marx, entonces, señala la opresión que ejerce el Estado sobre ambas: «el Estado brota de aquí de un modo inconsciente y arbitrario. La familia y la sociedad civil aparecen como el sombrío fondo natural sobre el cual derrama su luz el Estado». ${ }^{36}$ Critica que el Estado sea

30 MARX, K., Crítica a la filosofía del Estado de Hegel, op. cit., p. 14.

31 Ibid., p. 109.

32 HEGEL, G. W. F., Principios de la filosofía del derecho, op. cit., §268.

33 Ibid., \$269 añadido.

34 MARX, K., Crítica a la filosofía del Estado de Hegel, op. cit., p. 20.

35 Ibid., p. 22.

36 MARX, K., Crítica a la filosofía del Estado de Hegel, op. cit., p. 14. 
la potencia superior de la que dependen ambos momentos para realizar su eticidad. Que la voluntad general y la libertad solo se puedan dar en el Estado, dice Marx, anula la dimensión política de los momentos previos, los convierte en predicados, «la condición pasa a ser condicionado». ${ }^{37}$ La lógica deja echado un velo sagrado sobre la política que la mistifica; queda así condensado «todo el misterio de la filosofía del derecho y de la filosofía hegeliana en general». ${ }^{38}$ Marx, a través de Feuerbach, ve cómo Hegel ha traído de vuelta las lógicas religiosas al hacer girar en torno al Estado toda la política, como si fuera el nuevo sujeto absoluto de la política en vez de tener la forma del hombre, mientras que, en contraposición, dice: «al igual que en la crítica de la religión llevada a cabo por Feuerbach, nuestra finalidad no es otra que la de conducir a forma humana autoconsciente todas las cuestiones religiosas y políticas». ${ }^{39}$

En este sentido, la principal ruptura metodológica viene ejemplificada en el siguiente párrafo:

la crítica verdaderamente filosófica de la constitución actual del Estado no se limita a demostrar que las contradicciones existen, sino que las explica, comprende la génesis, la necesidad de las mismas. Las considera en su propia significación. Pero este entendimiento no consiste, como cree Hegel, en reconocer en todas partes las determinaciones del concepto lógico, sino en concebir la lógica especial del objeto especial. ${ }^{40}$

O dicho con el mantra político de Lenin, el análisis concreto de la realidad concreta. Aquí yace la fundamental diferencia entre la dialéctica de Hegel y la de Marx que a lo largo de los años irá perfeccionando pero que nunca dejará de ser deudora de Hegel. Marx quiere derivar la universalidad del objeto a partir de su propia constitución mientras que Hegel, a juicio de Marx, trata de derivar la existencia del objeto de la naturaleza del concepto, esto es, el destino del objeto queda «sellado en los sagrados registros de la Santa Casa de la Lógica». ${ }^{41}$ El objeto queda reducido no al inicio de la experiencia sino a una forma pasiva que permite el despliegue de la idea, la lógica ya ha determinado previamente a las realidades empíricas. Por eso Marx le achaca que el espíritu cae en el empirismo vulgar o el materialismo grosero, porque adopta acríticamente la existencia empírica.

37 Ibid., p. 16.

38 Ibid., p. 17.

39 Marx en su carta a Ruge desde Kreuznach, septiembre de 1843: MARX, K., y RUGE, A., Los anales franco-alemanes, op. cit., p. 69.

40 MARX, K., Crítica a la filosofía del Estado de Hegel, op. cit., p. 114.

41 Ibid., p. 23. 


\section{Estado y sociedad civil, y viceversa}

Frente a esas interpretaciones que consideran al Estado como la encarnación de la Idea que subsume sus momentos anteriores baste decir unas palabras para defender a Hegel. En línea con la crítica a las éticas formalistas, contra las que se posiciona claramente en el prólogo de la Filosofía del derecho, que elevan los fundamentos del obrar a una suerte de ecúmene moral, la libertad que ahora «ha devenido mundo existente» ${ }^{42}$ no puede sostenerse en la subjetividad y el capricho, sino que existe un fondo estable y objetivo: «las instituciones y leyes existentes en y por sí». ${ }^{43}$ Por eso, el último momento de la eticidad, tras la familia y el vínculo de amor, y el momento de intereses particulares y económicos (sociedad civil), tiene que ver con el libre sometimiento racional a los poderes políticos (Estado).

El Estado, entonces, es la sustancia ética, lo en sí y para sí racional y la más alta instancia de la libertad concreta. La libertad individual concreta no es un mero arbitrio subjetivo, sino que es verdadera libertad cuando se inserta en la libertad de las instituciones políticas que le permiten desplegar todo su potencial; tenemos en Hegel una alabanza de las instituciones estatales y desde luego no del estado liberal atomístico. Frente a la común idea liberal de que habría que sacrificar parte de la libertad individual para formar un Estado, este dirá que no es sacrificar sino realizarla efectivamente en el marco de una comunidad política.

Este marco es la adecuación de las formas del derecho y la ciencia política a su noción, esto es, la racionalidad suprime y eleva ciertos aspectos del contenido de estos conceptos para que puedan, así, cumplir todas sus potencialidades objetivas como Estado. No es una simple instancia superior que subsume sus dos momentos anteriores, sino que las asume y reformula y establece una nueva relación entre ellos, la familia y sociedad civil, y el Estado: cada uno refleja ahora desde su perspectiva a los otros dos.

Las personas, entendidas estas a la manera hegeliana, si solo se las entiende con referencia al momento subjetivo y formal, son meras abstracciones a las cuales Hegel se quiere oponer. Los sujetos solo adquieren su verdadera identidad y fondo mediante la integración en un sistema orgánico de interdependencia ${ }^{44}$ donde pueden ya reconocerse entre sí por cumplir ciertas funciones o roles dentro de la sociedad civil. Y solo aquí, en el sistema de las necesidades, y así, en el reconocimiento mutuo en el seno de la comunidad que satisface los intereses de todos, es cuando tiene sentido por primera vez hablar de hombre. ${ }^{45}$

42 HEGEL, G. W. F., Principios de la filosofía del derecho, op. cit., §142.

43 Ibid., $\$ 144$.

44 Ibid., $\$ 183$.

45 Ibid., $\$ 190$. 
Es cierto que el primer momento de la sociedad civil tiene que ver con la satisfacción de intereses y necesidades de unos sujetos orientados racionalmente en el mercado, pero de ningún modo termina aquí, sino que tiene como objetivo la satisfacción de las necesidades de todos los demás. No hay lugar, de nuevo, para una interpretación atomística-liberal del sujeto como un mero homo oeconomicus. Y para solventar la contingencia de la sociedad civil Hegel apuesta por las corporaciones y policía, ${ }^{46}$ aunque se da cuenta en la exposición de que el estamento principal de la sociedad moderna, el industrial (Fabrikantenstand), opera con unas lógicas - «insaciabilidad, desmesura y falta de límites en la acumulación de riqueza», ${ }^{47}$ amén de un «ansia de lujo y derroche de la clase industrial que se relaciona con el surgimiento de la plebe» ${ }^{48}$ que, sin embargo, no pueden ser auto-reguladas y que exigen salirse de la inmanencia del despliegue del espíritu objetivo hasta ahora y buscar una regulación en el siguiente momento, esto es, en el Estado.

Los individuos adquieren su verdadera realización en la sociedad civil y en el marco de una división social del trabajo donde por medio de su «actividad, diligencia y habilidad $»^{49}$ se convierten en pieza fundamental de un momento de la sociedad civil y pueden adscribirse a una clase -entendido aquí como estamento y no como Klasse; esta última denominación la reserva Hegel solo para cuando hace clasificaciones con criterio puramente económico- ya que sin esta el hombre es «una mera persona privada y no está en una universalidad real». ${ }^{50}$ Aquí entran las corporaciones como elemento de cohesión social y creador de cierta solidaridad comunitaria que permite desplegar la identidad y, sobre todo, y esta es la clave, hacer coincidir los intereses dispersos de los sujetos en un fin superior. ${ }^{51}$

Hegel anticipa de alguna manera en este sentido muchas de las caracterizaciones de Marx acerca del mercado. Ambos lo entienden como la apariencia de una estructura más profunda que, si bien para Hegel son los estamentos armónicamente organizados, para Marx es el conflicto irresoluble - desde los propios parámetros de la sociedad civil- entre clases. ${ }^{52}$

Valga esta breve argumentación para refutar gran parte de la crítica de los primeros párrafos del manuscrito antes expuesta. De hecho, en Hegel el Estado no tiene como fin la coerción y subsunción de los momentos inferiores, sino que

46 Ibid., $\$ 188$.

47 DUQUE, F., Eticidad y estado en el idealismo alemán, op. cit., p. 146.

48 HEGEL, G. W. F., Principios de la filosofía del derecho, op. cit., §25.

49 Ibid., $\$ 207$.

50 Íbidem.

51 Ibid., § 249.

52 WOODS, A., Hegel and Marxism, en: BEISER, F. (Ed.), Cambridge companion to Hegel, Cambridge University Press, Cambridge, 1993, pp. 421-422. 
es la máxima realización de la libertad donde el bienestar y felicidad de los sujetos es absolutamente indispensable para el buen funcionamiento del estado.

Se ha dicho con frecuencia que la finalidad del Estado es la felicidad de los ciudadanos. Esto es evidentemente cierto en la medida en que, si no se sienten bien con él, si no se satisface su fin subjetivo, no considerarán que el Estado como tal es la mediación de esa satisfacción, con lo cual éste estará asentado sobre cimientos poco sólidos. ${ }^{53}$

Tanto la felicidad como el bien particular son necesarios para el Estado, lo único que está apuntando Hegel, en línea con Aristóteles, es que es en el Estado -en la polis- donde el hombre puede realizarse al completo, donde puede alcanzar su más elevado fin y bien.

Lo novedoso de la perspectiva triádica de Hegel es que no necesita recurrir a una instancia externa para unir dos conceptos entre sí, familia y sociedad civil en este caso, sino que se resuelve desde una radical inmanencia. El Estado es el organismo más grande y articulado que se diferencia de cada uno de sus miembros sin anularnos: contiene en sí la diferencia. Y no solo porque la diferencia tenga derecho a existir -y esto es fundamental-, sino que es la existencia misma; el Estado vive de la armonización de las particularidades, crimen y dispersión de la sociedad civil, es decir, vive de la lucha reglada de clases.

En esta línea de refutación de la idea del monstruoso y divinizado Estado que fagocita a los sujetos se enmarca la lectura de Ilting de la crítica de Marx. ${ }^{54}$ En efecto, las primeras páginas del manuscrito corresponden a los desarrollos más feuerbachianos de Marx, y también a las más débiles, ya que parte de una interpretación sustancialista y panlogista de Hegel, presentando un sistema cerrado y dando lugar a numerosos malentendidos por intentar forzar la argumentación hegeliana para que encaje con sus críticas. Aun así, lo valioso del texto reside, también, en las siguientes páginas, cuando entra en juego la propiedad privada y la crítica al poder legislativo, y la democracia; veamos en qué sentido.

\section{Critica a las tres mediaciones del Estado con la sociedad civil}

A) El poder principesco. Si la universalidad es competencia del momento legislativo que se encarga de establecer lo universal, y lo particular se encuentra en el

53 HEGEL, G. W. F., Principios de la filosofía del derecho, op. cit., \$265.

54 ILTING, K.-H., «Hegel on the state and Marx's early critique», en: PELCZYNSKI, Z. A. (Ed.), The State and Civil Society. Studies in Hegel's Political Philosophy, Cambridge University Press, Cambridge, 1984, pp. 93-114. 
poder gubernativo como aplicación del universal con vistas a particularizarlo, lo singular, en consecuencia, la autodeterminación, es el poder del soberano. Y esta determinación de la voluntad que se realiza a sí misma no puede sino tener la forma de la subjetividad, de un yo que es a la vez lo más particular y lo más universal. ${ }^{55}$ Es la realización de la voluntad, entendida esta como la capacidad del hombre de hacer pasar de algo inteligible o posible a algo existente, del pensamiento al acto, es la realización del yo como existencia. La voluntad, aunque parezca tautológico, engendra al yo, es decir, no hay un yo sin un yo quiero. Existen las leyes en las cuales reside todo aspecto objetivo y sobre las cuales «el monarca solo tiene que agregarle el subjetivo "yo quiero" ". ${ }^{56}$ La subjetividad existe en tanto que se sabe a sí misma y sabe lo que quiere, y en la medida en que se concreta en un sujeto, esto es, en este caso, en el monarca.

Hegel echa mano de lo empírico, de los estados realmente existentes, pero no para establecer un mero deber ser sino para contraponerlos y exprimir de ellos lo racional que ya tenían dentro, pero de manera unilateral -y es solo en este sentido como hay que entender el papel de lo empírico en Hegel, no tanto como Marx le achaca. Precisamente no se queda en lo empírico, sino que quiere ir más allá y desentrañar en ello lo racional. En este sentido, los principales competidores de Alemania, Inglaterra y Francia, son la prueba palmaria de que el único modo de gobierno que puede garantizar la libre existencia de todos los conceptos y la realización de los principios jurídicos es la monarquía constitucional. ${ }^{57} \mathrm{La}$ historia universal general cuyo objeto es el despliegue de la idea de monarquía constitucional ha pasado por sucesivos momentos hasta alcanzar la infinitud. ${ }^{58} \mathrm{Ni}$ Inglaterra, con una monarquía débil que no pudo efectuar el paso del absolutismo feudal a la monarquía constitucional y acabó retrasada con respecto al derecho civil y penal, ${ }^{59}$ ni Francia, que cortó la cabeza del rey y dejó al pueblo gobernar en base al terror y la limitación de libertades, son los modelos políticos. En cambio, Alemania tiene las bases materiales e históricas para hacer que culmine en ella todo el mundo moderno político, en una monarquía constitucional, que es a lo que Hegel aspira.

Este apela a un carácter meramente simbólico del soberano que solo habría de sancionar los síes poniendo el punto sobre la í, pues su validez no depende de su formación o de la particularidad de su carácter sino de su posición. ${ }^{60}$

55 HEGEL, G. W. F., Principios de la filosofía del derecho, op. cit., §275 añadido.

56 Ibid., $\$ 280$ añadido.

57 Los principios jurídicos, a saber: «los principios de la libertad de la propiedad y, sin mayores precisiones, de la libertad personal, de la sociedad civil y su creatividad, de las corporaciones locales, como también de la actuación de las autoridades particulares, regulada por las leyes y de ellas dependiente». HEGEL, G.W. F., Enciclopedia de las ciencias, Abada, Madrid, 2017, §544.

58 HEGEL, G. W. F., Principios de la filosofía del derecho, op. cit., §273.

59 HEGEL, G. W. F., Enciclopedia de las ciencias, op. cit. \$544.

60 HEGEL, G. W. F., Principios de la filosofía del derecho, op. cit., \$280. 
El monarca no es solamente el resultado de la interacción entre el gobierno y las cortes, sino que es aquel que permite, precisamente, que estas existan, de tal manera que el monarca es el punto de inicio que no puede ser deducido, sino que comienza a partir de sí mismo. Sin embargo, replica Marx, si en un primer momento hubiera situado la soberanía del Estado no en el príncipe sino en el pueblo, en los sujetos reales, no se necesitaría subjetivar de manera mística al monarca.

La función del monarca en el sistema político de Hegel es, como vemos, de una importancia capital. Función que, paradójicamente, señala Marx, se pretende derivar de la Idea, pero se deja al puro arbitrio y al azar del nacimiento. Por lo tanto, en «la cúspide del Estado no decidiría, pues, la razón sino la simple naturaleza. El nacimiento determinaría la calidad del monarca, como determina la calidad del ganado». ${ }^{61}$ Además, prosigue Marx:

Hegel convierte en autodeterminaciones absolutas de la voluntad a todos los atributos del monarca constitucional de la Europa actual. No dice: la voluntad del monarca es la última decisión, sino: la última decisión de la voluntad es el monarca. La primera frase es empírica y la segunda desnaturaliza el hecho empírico y hace de él un axioma metafísico. ${ }^{62}$

El monarca queda por encima del gobierno, siendo los funcionarios los que rinden pleitesía real y política a este.

Las críticas de Marx en cuanto a la arbitrariedad y el azar, tanto de la voluntad como del nacimiento, son a menudo aceptadas; sin embargo, que el príncipe se erija por encima del gobierno no acaba de convencer a algunos hegelianos. De esta opinión es Bernard Bourgeois, ${ }^{63}$ ya que parece que Marx olvida que es un príncipe constitucional y que está en relación dialéctica con los demás polos, en el sentido de la tríada trinitaria donde cada uno no se entiende sin el otro: no hay preminencia de uno sobre otro. Ciertamente Hegel es difícil de criticar, pareciera como un erizo que pincha lo toques por donde lo toques. Además, una crítica a una parte de su teoría, por pequeña que sea, te redirige enseguida a otras partes del gran sistema.

Aunque no deja de ser curioso que muchos hegelianos se amparen en esta consistencia lógica del sistema para, a veces, defender lo indefendible; que algo tenga coherencia interna no quiere decir que sea verdad. Indudablemente el príncipe en este caso, aunque podríamos hablar, también, por ejemplo, de la posición de la mujer en la Fillosofía del Derecho, cumple un papel necesario en

61 MARX, K., Crítica a la filosofía del Estado de Hegel, op. cit., p. 45.

62 Ibid., p. 35.

63 BOURGEOIS, B., «El príncipe hegeliano», en: AMENGUAL, G. (Ed.), Estudios sobre la Filosofía del derecho de Hegel, Centro de Estudios Constitucionales, Madrid, 1989, p. 308. 
el armónico sistema, pero no por ello está exento de ser repensado y reformado, ni las críticas salen repelidas a gran velocidad en cuanto tocan la superficie del sistema hegeliano.

B) Poder gubernativo. El Estado se sirve de los funcionarios para poder manifestarse como una potencia efectiva, no son una mera correa de transmisión sino la misma condición de existencia del Estado, esto es, los funcionarios son el Estado. Hegel otorga a los funcionarios una posición de suma importancia: la del término medio. Es el término que abnegadamente desaparece en el silogismo pero que consigue unir la premisa mayor y la premisa menor, es el que, en última instancia, pone todo el sistema en movimiento. Permite la relación entre el poder gubernativo, en sentido alto, el ejecutivo, y el poder legislativo, que a su vez es una emanación de las corporaciones, municipios, en definitiva, de lo local, que intenta ser escuchado por el monarca. El poder gubernativo tiene una tarea clara: reforzar el lazo ético que une al Estado frente a las constantes amenazas de los intereses particulares que provienen de la sociedad civil. Para poder actuar sobre la sociedad civil el poder gubernativo despliega al estamento del funcionariado que no se identifica con intereses particulares, sino que hace valer los universales, esto es, los intereses de todos los ciudadanos coinciden con los de los funcionarios - al fin y al cabo, Hegel pertenecía a esta clase como profesor de universidad, es comprensible que le diera tanta importancia y que restringiera el acceso al estamento a solo unos pocos formados.

Los burócratas, entonces, son la clase universal. ¿Significa esto que la filosofía solo puede ser ejercida dentro de los límites del Estado? ¿Qué hay de la libertad del filósofo para criticar? Ciertamente la formulación de Hegel parece indicar esto; Platón se escandalizaría al ver que el papel del filósofo es este y que en lugar del Filósofo-Rey habría un monarca de dudosas capacidades únicamente poniendo su firma en documentos. El poder gubernativo, el Estado en última instancia, se mediatiza con la sociedad civil mediante los funcionarios, pero lejos de solucionar la oposición sociedad civil-Estado, simplemente le da una forma legal y la perpetúa del lado de los funcionarios. ${ }^{64}$

El comentario de Marx a los parágrafos del poder gubernativo empieza nada menos que de la siguiente manera: «lo que Hegel dice del poder gubernativo no merece el nombre de exposición filosófica. La mayoría de los parágrafos podrían figurar literalmente en el código civil prusiano». ${ }^{65}$ Una fuerte crítica que señala con meridiana claridad la caracterización que el joven Marx hace de la filosofía política de Hegel.

Marx arremete contra la burocracia y tecnocracia de los funcionarios como estamento de expertos que resta soberanía del pueblo al recaer sobre ellos el

64 MARX, K., Crítica a la filosofía del Estado de Hegel, op. cit., p. 64.

65 Ibid., p. 58. 
garantizar la estructura política del Estado. Los burócratas, los funcionarios, son como los sacerdotes del Estado ${ }^{66} \mathrm{El}$ ciudadano queda sustraído de labores políticas, no se puede autodeterminar porque sus acciones son determinadas desde un afuera que opera desde un saber de carácter tecnocrático. Además, aquella clase universal sin intereses particulares está reservada, naturalmente, al proletariado, tal como dirá un año después en la Introducción. De tal manera que, de nuevo la lógica estaba detrás de todo: «Hegel da a su lógica un cuerpo político, no da la lógica del cuerpo político». ${ }^{67}$ Esta frase resume la inversión metodológica que querría Marx aplicada a un ámbito concreto, y su ruptura con Hegel.

C) Poder legislativo y estamentos. La parte de la crítica dedicada a los estamentos y al poder legislativo es la más provechosa y también la más interesante. Desde las coordenadas del joven Marx, el problema subyace en que Hegel empuja hacia abajo los intereses y la propiedad privados y los confina a los particulares límites de la sociedad civil de tal forma que no queda mácula en el lustroso Estado que, ahora sí, queda por encima de las particularidades y puede armonizar las determinaciones de la sociedad civil. De esta manera, Hegel pretende eliminar las interferencias que los hombres privados pudieran provocar en el desarrollo de estos en ciudadanos, haciendo imposible desde esta perspectiva atisbar cualquier contradicción entre sociedad civil y Estado o entre -y simplificando- lo económico y lo político.

Los estamentos median entre el gobierno y el pueblo, y exigen a las personas participar de ambos polos tanto como ciudadanos del Estado como representantes de los intereses personales y de sus círculos cercanos, ${ }^{68}$ de manera que la balanza no se incline del lado del gobierno o del príncipe ni del lado de la sociedad civil.

La común idea de que las clases privadas de la sociedad civil participan de los asuntos del poder legislativo como individuos atomísticamente separados es combatida por Hegel afirmando que efectivamente participan como miembros de un universal. ${ }^{69}$ Es decir, no es una yuxtaposición o agregado abstracto de individuos, sino que a la luz del Estado adquieren una significación colectiva cualitativamente distinta. Y en ese sentido no se produciría aquí una radical escisión entre las clases (Stände) de la sociedad civil y los estamentos (Stände) políticos - tal como señala Vermal, ya que en Hegel ambos sentidos están ligados y se usan indistintamente para lo civil y lo político. ${ }^{70}$ Pero para Marx la distinción entre ambos lo es todo. Tras la Revolución Francesa no se puede

66 Ibid., p. 60.

67 Ibid., p. 63.

68 HEGEL, G. W. F., Principios de la filosofía del derecho, op. cit., §302.

69 Ibid., $\$ 303$ nota.

70 Ibid., nota del traductor en la p. 320. 
dejar en la indeterminación el concepto de Stände, fue este acontecimiento el que los separó finalmente de la unidad que conformaban en la edad media. ${ }^{71}$ Sin embargo, Hegel sigue aferrándose de manera ciertamente anacrónica a una distinción medieval.

Además, que los individuos participen a través de las corporaciones y estamentos en la política excluye necesariamente a aquellos individuos que no son amparados por estas instituciones. Y Hegel, como desde luego Marx, reconoce que hay personas excluidas cuando caen por debajo de un umbral de subsistencia, ${ }^{72}$ viéndose privados de derechos, honor y de estatus como persona al no poder ganarse la subsistencia por medio de su trabajo; la riqueza de la sociedad civil solo es riqueza que se acumula en pocas manos y no puede impedir la formación de la plebe. ${ }^{73}$ De hecho, la sociedad civil es forzada a buscar soluciones más allá de sus propias determinaciones y salir a buscar otros mercados en otras sociedades menos avanzadas, ${ }^{74}$ de manera que el colonialismo -o el imperialismo diríamos ahora- es la consecuencia lógica de las dinámicas industriales de la sociedad civil. ${ }^{75} \mathrm{Y}$ aquí Hegel es, podríamos decir, más marxista que Marx, ya que anticipa una teoría del imperialismo mucho antes de que Marx pensara en ello, una teoría que, de hecho, inspira hasta cierta medida a Rosa Luxemburgo, casi cien años después. ${ }^{76}$

Sin embargo, la crítica al mayorazgo es el punto más pulido de la crítica de Marx a Hegel, y en donde se ven más claramente una serie de desarrollos aquí in nuce pero que a lo largo de su vida desarrollaría. Así como Marx había señalado la arbitrariedad y azar del monarca como representante de la voluntad del Estado, ocurre algo similar en la institución del mayorazgo. Heredar la propiedad de la tierra tiene en común la misma contingencia que heredar la corona. También Hegel señala la continuidad entre ambos - aunque no de un modo despectivo; los dos tienen la determinación natural y la voluntad del yo quiero. La cuestión es que, de nuevo, el insigne desarrollo del espíritu objetivo se estrella en el materialismo más grosero ${ }^{77}$ por dejar tamaña función social al arbitrio del nacimiento, de la pura corporalidad. El estado está más

71 MARX, K., Crítica a la filosofía del Estado de Hegel, op. cit., p. 100.

72 HEGEL, G. W. F., Principios de la filosofía del derecho, op. cit., \$244.

73 Ibid., \$245. Al no tratar directamente Marx de esto en su crítica no se hará un análisis exhaustivo de la cuestión, pero qué duda cabe que es fundamental para entender bien la relación entre ambos; se puede ver con el asunto de la plebe que este es uno de los casos en que Marx lleva hasta las últimas consecuencias los desarrollos ya iniciados por Hegel. Para un fantástico análisis detallado de esta cuestión véase el trabajo de RUDA, F., Hegel's Rabble, Continuum, London/New York, 2011.

74 HEGEL, G. W. F., Principios de la filosofía del derecho, op. cit., \$246.

75 Ibid., $\$ 248$.

76 HIRSCHMAN, A., «On Hegel, imperialism, and structural stagnation», Journal of Development Economics 3, 1976, pp. 1-8.

77 MARX, K., Crítica a la filosofía del Estado de Hegel, op. cit., p. 133. 
cerca de la animalidad, ya que estos obtienen sus determinaciones mediante el nacimiento. «La naturaleza se venga de Hegel por el desprecio que manifiesta hacia ella», ${ }^{78}$ se mofa Marx.

El mayorazgo es la constitución política de la nobleza que se erige en una eticidad natural y subsiste gracias a la propiedad raíz. ${ }^{79}$ De hecho, goza de una posición, en cierto sentido, privilegiada porque, dice Hegel, su patrimonio no está enmarcado en las lógicas industriales animadas por el irrefrenable deseo de ganancia, ni tampoco sujeto a la colectividad del patrimonio estatal. Pero para poder mantenerse vivos entre ambos, han de preservar la institución inalienable del mayorazgo. ${ }^{80}$

El mayorazgo es la apariencia de algo más profundo, de la propiedad de la tierra. Al hacerlo inalienable, Hegel imposibilita la relación social de esta institución con las demás, la naturaliza con respecto a la sociedad civil. Y aunque señala que el mayorazgo está por encima del amor del padre a sus hijos y que irremediablemente tendrá que traspasar sus bienes al primogénito, no quiere admitir que esto rompa con los lazos familiares y el amor. Cuestión que ya se encarga Marx de señalar: «En la clase que tiene por base la vida de familia, falta pues la base de la vida de la familia, el amor como principio real, es decir, eficaz y determinante. En su mayor desenvolvimiento, el principio de la propiedad privada contradice al principio de la familia». ${ }^{81}$ La propiedad privada se inmiscuye en las relaciones afectivas anulándolas y dirigiéndolas hacia unos objetos externos que se escapan al control de las voluntades de las familias. Se empieza a entrever cierta teoría de la cosificación y mistificación, clara herencia feuerbachiana, que naturalmente no se hará esperar mucho -en 1844 escribe los Manuscritos económico-filosóficos donde presenta una teoría de la alienación. Y que concluirá en el fetichismo de la mercancía de El capital como expresión máxima de una racionalidad abstracta que domina de forma anónima y de la cual la burguesía no es más que su fenómeno externo.

Voluntad y posesión se invierten, la voluntad ya no engendra al yo mediante la apropiación sino la voluntad ahora es «en tanto que ella está colocada en la propiedad. Mi voluntad no posee aquí; es poseída». ${ }^{82}$ En el mayorazgo la voluntad languidece, se limita, pierde la soberanía y se convierte en la más alta síntesis de la alienación de lo arbitrario, de suerte que recubre la relación del mayorazgo con un halo religioso.

El mayorazgo es la constitución política de la nobleza, señalaba Hegel, pero una vez ha establecido relación directa entre el mayorazgo, una institución

78 Ibid., p. 131.

79 HEGEL, G. W. F., Principios de la filosofía del derecho, op. cit., §305.

80 Ibid., $\$ 306$.

81 MARX, K., Crítica a la filosofía del Estado de Hegel, op. cit., p. 123.

82 Ibid., p. 126. 
dominada por la propiedad privada inalienable, con el Estado político, ya no hay vuelta atrás. El Estado político que debía velar por mantener el equilibrio en la balanza del universal y el particular es tomado, a juicio de Marx, por la propiedad privada abstracta haciendo que este garantice y perpetúe su existencia. El Estado, la sustancia ética en sí y para sí, es ahora un accidente de la propiedad privada. Lo determinante pasa a ser determinado. Este punto sienta las bases para la posterior consideración del Estado como el consejo de administración de la burguesía, faltaría solo la caracterización sociológica de la burguesía como clase.

\section{La propuesta política de Marx: democracia radical}

Finalmente, creemos provechoso destacar la cuestión de la democracia como ámbito de realización efectiva para Marx de lo particular y lo universal; la propuesta política de este será la de una teoría de la democracia radical bajo un Estado republicano, fruto de situar al hombre como sujeto de la política. Es relevante porque a lo largo de la crítica adopta un carácter más destructivo que constructivo; sin embargo, hay un breve intento de plantear soluciones.

Ciertamente el joven Marx es un republicano radical, cercano al jacobinismo, es decir, un liberal radical durante todo el periodo de la Rheinische Zeitung. No se despega de ciertas concepciones idealistas hegelianas, ya que sigue considerando el Estado como el lugar de la máxima expresión de la razón ${ }^{83}$ pero que no sería ya el Estado monárquico y constitucional de Hegel, ni mucho menos el Estado concreto prusiano (que le expulsa de allí y se ve forzado a huir a Francia), sino el Estado democrático. Es necesario romper con la alienación del hombre con respecto su esencia genérica (Gattugswessen). Esta tarea podría llevarse a cabo únicamente al abolir la propiedad privada en el marco de un Estado republicano democrático. El fundamento de esta enajenación se encuentra en que el Estado está despegado de los hombres particulares y solo cuando estos tomen la soberanía del Estado podrán realizarse. Marx, en un claro ejercicio idealista, aboga por la toma de conciencia de la esencia humana para luego transformar la realidad:

La razón ha existido siempre, pero no siempre en forma racional. De modo que el crítico puede remitirse a cualquier forma de conciencia teórica y práctica, y a partir de las formas propias de la realidad existente, desarrollar la verdadera realidad en cuanto deber y objetivo teológico. Por lo que

83 Idea que se puede derivar de la lectura de los tempranos artículos sobre la libertad de prensa, como «Los debates sobre la libertad de prensa y la publicación de los debates de la Dieta»; MARX, K., Escritos de juventud, op. cit., pp. 173-220. 
se refiere a la vida real, lo que contiene en todas sus formas modernas las instancias de la razón es, precisamente, el Estado político, aun cuando todavía no conscientemente sensible a las instancias socialistas. ${ }^{84}$

Por mucho que Marx oponga una férrea oposición a Hegel, estas palabras y esta manera de entender la praxis política y el Estado son completamente hegelianas. Sin embargo, en última instancia, la crítica de Marx a Hegel radica en haber hecho del Estado el lugar de la autodeterminación política de la comunidad. La soberanía no radica en el pueblo que luego se concretiza en forma de leyes del estado de derecho, sino que es directamente el Estado la fuente de soberanía. Hegel realiza la crítica a la soberanía desconfiando de la masa que no es capaz de autodeterminarse y que, si aun así se apuesta por las masas para dirigir la política, a lo más que se llegaría es a una oclocracia, a una tiranía de estas. ${ }^{85}$ La verdadera soberanía reside en el Estado dirigido por el monarca, que es el verdadero poder constituyente. El pueblo no puede constituir el Estado porque no existe el afuera del Estado. Marx, sin embargo, argumenta que la sociedad, el dêmos, previamente se ha instituido como poder político constituyente.

La democracia, a diferencia de como se ha entendido en toda la tradición del pensamiento político, no es una forma más de gobierno que coexiste con la monarquía, la aristocracia, etc. La democracia es el telos de todas las formas políticas de gobierno: «la democracia es la verdad de la monarquía, pero la monarquía no es la verdad de la democracia». ${ }^{86}$ La monarquía es una forma alienada de la democracia, es una democracia que no es en sí, sino que está, aún, fuera de sí. Con esta forma de gobierno, el pueblo presenta su existencia en un modo no acabado, mientras que en democracia emerge la constitución del pueblo. La democracia se puede conocer a sí misma, se puede autoconstituir alcanzando a ser, por fin, mediante la mediación, entre universal y particular, la constitución genérica. Efectivamente, en una monarquía o en una república simplemente formal, el hombre político (citoyen) convive con el hombre privado (bourgeois) pero mantienen una radical escisión. No se trata, tampoco, de establecer una mera republica formal como la de Norteamérica, porque el contenido último de esta y de la monarquía prusiana es el mismo. Se trata de reconciliar la esencia política del hombre como ser genérico, de realizarse como sujeto social y político; así, la democracia es «el enigma resuelto de todas las constituciones». ${ }^{87}$

84 Marx en su carta a Ruge desde Kreuznach, septiembre de 1843, MARX, K., y RUGE, A., Los anales franco-alemanes, op. cit., pp. 67-68.

85 HEGEL, G. W. F., Principios de la filosofía del derecho, op. cit., \$279.

86 MARX, K., Crítica a la filosofía del Estado de Hegel, op. cit., p. 40.

87 Ídem. 
Solo en el discurrir de la historia la democracia se va desplegando hasta que un pueblo adquiere la suficiente conciencia de su esencia política como para autodeterminarse, como para darse a sí mismo su soberanía política. En última instancia, si la toma de conciencia de sí es lo fundamental de la modernidad, que el hombre pueda autodeterminarse políticamente es la mayor expresión de libertad política. En Hegel la masa no sabe lo que quiere; en Marx la masa tiene potencialidades internas que aún no sabe desplegar.

Finalizando, una vez más, con el argumentario feuerbachiano: mientras los pueblos tengan un gobierno monárquico, aristocrático, etc., estos estarán alienados con respecto a su esencia política de la misma manera que la religión aliena al sujeto de su condición de ser humano al negar en él lo que afirma en Dios. «Hegel parte del Estado y convierte al hombre en el Estado subjetivado; la democracia parte del hombre y convierte al Estado en el hombre objetivado. Así como la religión no crea el hombre, sino que es el hombre el que crea la religión, así también la constitución no crea el pueblo, sino que es el pueblo el que crea la constitución». ${ }^{88}$

Marx (y Feuerbach) hizo bien en dedicar gran parte de sus esfuerzos en criticar que las lógicas religiosas nunca se habían ido por completo, ya sea ejemplificadas en Hegel como en la misma institución eclesiástica. Eventualmente el carácter reaccionario de esta última se reafirmó sepultando bajo sus cimientos a los muertos de la primera experiencia revolucionaria verdaderamente obrera. La basílica del Sacré-Cœur de París ha enterrado a la Comuna de París, solo el curso de la historia podrá probar si son inertes restos olvidados o una poderosa semilla.

\section{Conclusión: hacía un marxismo hegeliano}

Como hemos apuntado, el manuscrito supone un interesante escalón en la evolución filosófica y teórica de Marx. Veíamos que, para Marx, siguiendo a Feuerbach, Hegel había invertido el sujeto en objeto, y a raíz de la crítica a esto, Marx había sentado las bases para una posterior ruptura metodológica. Además, había puesto de relieve la arbitrariedad y el azar en el corazón mismo de la filosofía política de Hegel, en el poder principesco, y desvelado la tecnocracia con la que operaba la autoproclamada clase universal del funcionariado. Además, lejos de que el Estado pudiera armonizar las particularidades de la sociedad civil, era la propiedad privada la que determinaba al Estado, cuya mejor ejemplificación la teníamos en la cuestión del mayorazgo. Finalmente, hemos discutido la propuesta política de Marx de un Estado democrático y republicano. Ciertamente en la argumentación del joven Marx 
hay notorias lagunas y fallos de interpretación que hemos ido exponiendo, pero también interesantes críticas y análisis.

Lo que está claro es que sería impensable hablar de Marx sin hacer referencia a Hegel; aun así, hay quienes, en un tono más vulgar, entienden que Marx «llevaba razón» y que su crítica ha conseguido la Aufhebung de toda su obra. Casi por el simple hecho de que Marx venía cronológicamente detrás de Hegel, en una suerte de progreso lineal del conocimiento. A grandes rasgos este es el pecado de muchos Partidos Comunistas que ven en Hegel una reliquia de la cual Marx salió pero que rápidamente se escindió y a la que no hay necesidad de volver porque todo lo que dijo Hegel ya está mejorado y libre de formulaciones idealistas en Marx - haciendo uso de una dupla materialismo-idealismo, de forma aún más tosca donde el materialismo es la simple preeminencia de la materia frente a la idea y el idealismo al contrario, sustituyendo un monismo por otro, es decir, siguiendo la estela del Diamat y su versión ramplona de Engels y Plejanov, y por supuesto, de Hegel y Marx.

Por el contrario, la postura a la que nos adscribimos es la de la «New Dialectic» o «New Hegelian Marxism», que no es tanto una escuela de pensamiento como una etiqueta que comprende diferentes aproximaciones cuyo tronco común es la revitalización de la filosofía política de Hegel y Marx a través de Ciencia de la lógica, esto es, una lectura no tan centrada en rescatar la Historia hegeliana y el nexo con el Materialismo Histórico -lectura característica de las relaciones Hegel-Marx de la segunda mitad del siglo xx- sino en la Lógica y sus desarrollos en El capital. En El capital Marx lleva hasta las últimas consecuencias muchos de los desarrollos de Hegel sobre la sociedad civil, manteniendo prácticamente intacta la Lógica. ${ }^{89}$

Cabe recordar la famosa primera edición alemana de El capital (1867) cuyo primer capítulo Marx lo escribe, ya no solo en parágrafos siguiendo una estructura típicamente hegeliana sino plagado de expresiones como en sí, para sí, etc., y utilizando conceptos y estructuras de la Lógica de Hegel. No en vano dijo Lenin, ávido lector de Hegel, «es completamente imposible entender El capital de Marx, y en especial su primer capítulo, sin haber estudiado y entendido a fondo toda la Lógica de Hegel. iiPor consiguiente, hace medio siglo ninguno de los marxistas entendía a Marx!!». ${ }^{90}$

Cuando Hegel desarrolla su pensamiento el incipiente capitalismo aún no era el de la época de Marx, mucho menos el actual. Una de las posibles reactualizaciones de la Filosofia del derecho pasa por esta interpretación de Hegel desde el marxismo como un sistema abierto -y no clausurado como al principio del artículo se explicaba. De hecho, otros hegelianos de renombre, como Robert Pippin, no necesariamente vinculado a esta corriente, también reconocen la

89 Véase, ARTHUR, C. J., The New Dialectic and Marx's Capital, Brill, Leiden/Boston, 2004.

90 LENIN, V., Obras completas, vol. XLII, Akal, Madrid, 1975, p. 172. 
imposibilidad de reconciliar el capitalismo industrial avanzado con el núcleo teórico hegeliano, y apuntan que la nueva lectura del hegelianismo marxista ha repensado en la correcta dirección esta cuestión. ${ }^{91}$ Diríamos en este sentido que es Hegel quien salva a Marx: es una profunda lectura de Hegel la que puede devolver al marxismo a la senda verdaderamente revolucionaria y no estancarse en oscuras concepciones pre-kantianas de la sustancia.

La Crítica a la filosofia del Estado de Hegel es un punto fundamental en esta lectura por ser de las primeras piedras en el camino del «New Hegelian Marxism», no en el sentido de una ruptura epistemológica entre el joven y el viejo Marx, sino del lugar donde se disputa por primera vez la dialéctica de Hegel y Marx; porque permite ver las limitaciones de la interpretación primera y feuerbachiana de Hegel, pero también porque pone los cimientos para que esa crítica a la lógica hegeliana adopte su forma final, más tarde, en la crítica a la economía política. 


\section{Bibliografía}

ARTHUR, G. J., The New Dialectic and Marx's Capital, Brill, Leiden/Boston, 2004.

AVINERI, S., Hegel's theory of the modern state, Cambridge University Press, New York, 1972.

BEISER, F., The Romantic Imperative, Harvard University Press, Massachusetts/London, 2003.

BOURGEOIS, B., «El príncipe hegeliano», en: AMENGUAL, G. (Ed.), Estudios sobre la Filosofia del derecho de Hegel, Centro de Estudios Constitucionales, Madrid, 1989.

CORNU, A., Carlos Marx y Federico Engels. Tomo I, Los años de infancia y de juventud. La izquierda hegeliana 1818/20-1844, Platina, Buenos Aires, 1965.

DUQUE, F., Eticidad y estado en el idealismo alemán, Natán, Valencia, 1987.

, Historia de la filosofia moderna. La era de la crítica, Akal, Madrid, 1998.

ENGELS, F., Escritos de juventud, Fondo de Cultura Económica, 1981.

FEUERBACH, L., Principios de la filosofia del futuro, Calden, Buenos Aires, 1969.

HEGEL, G. W. F., Principios de la Filosofia del derecho (trad. Juan Luis Vermal), Edhasa, Barcelona, 1999.

—_, Introducciones a la Filosofia de la Historia Universal, Istmo, Madrid, 2005.

—, Gesammelte Werke. Vorlesungen über die Philosophie des Rechts I: Kollegien der Jahre 1817/18, 1818/19, 1819/20, Felix Meiner Verlag, Berlin, 2014.

—_, Enciclopedia de las ciencias filosóficas, Abada, Madrid, 2017.

HIRSCHMAN, A., «On Hegel, imperialism, and structural stagnation», Fournal of Development Economics 3, 1976, pp. 1-8.

HOUlGate, S., The opening of Hegel's logic, Purdue University Press, Indiana, 2006.

ILTING, K.H., «Hegel on the state and Marx's early critique», en: PELCZYNSKI, Z. A. (Ed.), The State and Civil Society. Studies in Hegel's Political Philosophy, Cambridge University Press, Cambridge, 1984.

KOSELLECK, R., historia/Historia, Trotta, Madrid, 2010.

LENIN, V., Obras completas, Akal, Madrid, 1975.

LIEDMAN, S., Karl Marx, Akal, Madrid, 2020.

MARX, K., Crítica a la filosofia del Estado de Hegel, Grijalbo, México, 1974.

—- Escritos de juventud, Fondo de Cultura Económica, México, 1982..

—_, La ideología alemana, Akal, Madrid, 2014.

—_, El capital. Crítica de la economía política, Siglo XXI, Madrid, 2017.

MARX, K. y ENGELS, F. Marx \& Engels Collected Works, I, Lawrence \& Wishart, London, 1975.

MARX, K. y RUGE, A., Los anales franco-alemanes, Martínez Roca, Barcelona, 1970.

PIPPIN, R., «Did Hegel Comprehend His Own Time in Thought?», Estetica. studi e ricerche 10(2), 2020, pp. 571-588.

ROSSI, M., La scuola hegeliana. Il giovane Marx, Feltrinelli Economica, Milano, 1977.

RUDA, F., Hegel's Rabble, Continuum, London/New York, 2011.

RUIZ SANJUAN, C., Historia y sistema en Marx, Siglo XXI, Madrid, 2019.

WOODS, A., «Hegel and Marxism», en: BEISER, F. (Ed.), Cambridge companion to Hegel, Cambridge University Press, Cambridge, 1993. 
